\title{
The total energy of geomagnetic field
}

\author{
Gendenpuntsag Bayanjargal
}

Received: 8 February 2015/ Accepted: 11 May 2015/Published online: 13 June 2015

(C) The Author(s) 2015. This article is published with open access at Springerlink.com

\begin{abstract}
Geomagnetic field of Earth has been existed during the last three billion years. The geomagnetic field is a form of losing the geothermal energy of Earth. In this paper, the formula of total energy of geomagnetic field, which is used in the volume from the surface of Earth to unlimited space, is obtained by the function of scalar potential of IGRF (1900-2010). Generally, the total energy of geomagnetic field is decreasing by the linear form in these years. The general power of geomagnetic field about surface of Earth was also steady about $949.7 \mathrm{~kW}$. However, a damping oscillation form with about 60 year's period is appeared in the total energy of geomagnetic field. Maybe the damping oscillation form is sourced by effects of fluid motions on the core mantle boundary. Maybe the linear decreasing form in the total energy is the variation of the strong field sourced at the center of the Earth's inner core.
\end{abstract}

Keywords Total energy of geomagnetic field . Scalar potential for geomagnetic field

G. Bayanjargal ( $\square)$

Institute of Astronomy and Geophysics, Mongolian Academy of Sciences (MAS), Ulaanbaatar, Mongolia e-mail: gbayan27@yahoo.com

\section{Introduction}

Strong field is sourced by the dynamic processes in sub-shell of georeactor at the center of the Earth's inner core (Herndon 2009). The strong field spreads via the inner core, the liquid core, the mantle and the crust as well as it is observed as geomagnetic field.

The chain reaction's energy of nuclear fission of heavy nuclear isotopes (U-238, U-235 and Th-232) in georeactor becomes a main source of geothermal energy of Earth. The geothermal energy is lost by all geological activity phenomena such as volcanic activity, Earthquakes, continental drift and geomagnetic field. It is difficult that the total energy of volcanic activity, Earthquakes and the continental drift is estimated for whole Earth. The geomagnetic field is a form of losing the geothermal energy of Earth. However, the total energy of geomagnetic field solved for whole Earth is easier than others. The geomagnetic field of Earth has been also existed during the last three billion years. Therefore any phenomenon could be observed in the total energy of geomagnetic field.

Thus our purpose is to study the total energy of geomagnetic field for whole Earth. We are interesting the power of geomagnetic field about Earth's surface as well.

\section{To solve the total energy of geomagnetic field}

Gauss C.F included the method of spherical harmonic potential to the geomagnetism from the potential theory 
in 1839. This method obtains the scalar potential for geomagnetic field form the Laplace's equation. International Geomagnetic Reference Field (IGRF) is the negative spatial gradient of the scalar potential as well. It can be written as

$\overrightarrow{\mathrm{B}}=-\vec{\nabla} \mathrm{V}$

where $\mathrm{V}$-is the scalar potential for geomagnetic field solved form the Laplace's equation. And the V-is rewritten in the following form as

$$
\begin{aligned}
\mathrm{V}(\mathrm{r}, \theta, \varphi)= & \mathrm{a} \sum_{\mathrm{n}=1}^{\mathrm{k}}\left(\frac{\mathrm{a}}{\mathrm{r}}\right)^{\mathrm{n}+1} \sum_{\mathrm{m}=0}^{\mathrm{n}}\left(\mathrm{g}_{\mathrm{n}}^{\mathrm{m}} \cos (\mathrm{m} \varphi)\right. \\
& \left.+\mathrm{h}_{\mathrm{n}}^{\mathrm{m}} \sin (\mathrm{m} \varphi)\right) \mathrm{P}_{\mathrm{n}}^{\mathrm{m}}(\cos (\theta))
\end{aligned}
$$

here $\mathrm{a}$-is reference radius of Earth $(\mathrm{a}=6371.2 \mathrm{~km})$. The $r, \theta$ and $\varphi$ are the geocentric coordinates. $r$-is the radius in kilometers, $\theta$-is the co-latitude $\left(\theta=90^{\circ}-\right.$ latitude), and $\varphi$-is the longitude. The coefficients $\left(\mathrm{g}_{\mathrm{n}}^{\mathrm{m}}\right.$ and $\left.\mathrm{h}_{\mathrm{n}}^{\mathrm{m}}\right)$ are Gaussian coefficients put forth by the IAGA for the IGRF, and $\mathrm{P}_{\mathrm{n}}^{\mathrm{m}}(\cos (\theta))$ represents the Schmidt quasi-normalized associated Legendre functions of degree $\mathrm{n}$ and order $\mathrm{m}$.

If the Eq. (2) is substituted to the Eq. (1), the components of the Eq. (1) could be written as the following forms

$$
\begin{aligned}
\mathrm{B}_{\mathrm{r}}= & \frac{-\partial \mathrm{V}}{\partial \mathrm{r}}=\sum_{\mathrm{n}=1}^{\mathrm{k}}\left(\frac{\mathrm{a}}{\mathrm{r}}\right)^{\mathrm{n}+2}(\mathrm{n}+1) \sum_{\mathrm{m}=0}^{\mathrm{n}}\left(\mathrm{g}_{\mathrm{n}}^{\mathrm{m}} \cos (\mathrm{m} \varphi)\right. \\
& \left.+\mathrm{h}_{\mathrm{n}}^{\mathrm{m}} \sin (\mathrm{m} \varphi)\right) \mathrm{P}_{\mathrm{n}}^{\mathrm{m}}(\cos (\theta)) \\
\mathrm{B}_{\theta}=- & \frac{1}{\mathrm{r}} \frac{\partial \mathrm{V}}{\partial \theta}=-\sum_{\mathrm{n}=1}^{\mathrm{k}}\left(\frac{\mathrm{a}}{\mathrm{r}}\right)^{\mathrm{n}+2} \sum_{\mathrm{m}=0}^{\mathrm{n}}\left(\mathrm{g}_{\mathrm{n}}^{\mathrm{m}} \cos (\mathrm{m} \varphi)\right. \\
& \left.+\mathrm{h}_{\mathrm{n}}^{\mathrm{m}} \sin (\mathrm{m} \varphi)\right) \frac{\partial \mathrm{P}_{\mathrm{n}}^{\mathrm{m}}(\cos (\theta))}{\partial \theta}
\end{aligned}
$$

and

$$
\begin{aligned}
\mathrm{B}_{\varphi}= & \frac{-1}{\sin (\theta)} \frac{\partial \mathrm{V}}{\partial \varphi}=-\frac{1}{\sin (\theta)} \sum_{\mathrm{n}=1}^{\mathrm{k}}\left(\frac{\mathrm{a}}{\mathrm{r}}\right)^{\mathrm{n}+2} \\
& \times \sum_{\mathrm{m}=0}^{\mathrm{n}} \mathrm{m}\left(-\mathrm{g}_{\mathrm{n}}^{\mathrm{m}} \sin (\mathrm{m} \varphi)+\mathrm{h}_{\mathrm{n}}^{\mathrm{m}} \cos (\mathrm{m} \varphi)\right) \mathrm{P}_{\mathrm{n}}^{\mathrm{m}}(\cos (\theta))
\end{aligned}
$$

where $B_{r}, B_{\theta}$ and $B_{\varphi}$ represent the field strength in local tangential coordinates. $\mathrm{P}_{\mathrm{n}}^{\mathrm{m}}(\cos (\theta))$ is rewritten in the following form as

$$
\mathrm{P}_{\mathrm{n}}^{\mathrm{m}}(\mu)=\sqrt{\left(2-\delta_{\mathrm{m}}^{0}\right) \frac{(\mathrm{n}-\mathrm{m}) !}{(\mathrm{n}+\mathrm{m}) !}} \frac{\left(1-\mu^{2}\right)^{\mathrm{m} / 2}}{2^{\mathrm{n}} \mathrm{n} !} \frac{\partial^{\mathrm{n}+\mathrm{m}}}{\partial \mu^{\mathrm{n}+\mathrm{m}}}\left(\mu^{2}-1\right)
$$

here $\delta_{\mathrm{m}}^{0}$-is Kronecker delta and $\mu$ equals with $\cos (\theta)$ $(\mu=\cos (\theta))$ (Winch et al. 2005).

The Eq. (6) is called the quasi-normalized function of associated Legendre function.

Now, the density of energy of geomagnetic field could be solved from the Eqs. (3-5) as

$\mathrm{I}(\mathrm{r}, \theta, \varphi)=\frac{\mathrm{B}_{\mathrm{r}}^{2}+\mathrm{B}_{\theta}^{2}+\mathrm{B}_{\varphi}^{2}}{2 \mu_{0}}$

here $\mu_{0}$ equals $4 \pi \times 10^{-7} \mathrm{H} / \mathrm{m}\left(\mu_{0}=4 \pi \times 10^{-7} \mathrm{H} /\right.$ $\mathrm{m})$. In other word, the density of energy of geomagnetic field is solved how the Eqs. (3-5) are substituted to the Eq. (7). And the total energy of geomagnetic field could be solved from the Eq. (7) as

$\mathrm{W}=\int \mathrm{I}(\mathrm{r}, \theta, \varphi) \mathrm{dv}$.

To solve the integral in Eq. (8) is appeared difficulty. If the following orthogonal properties of quasi-normalized function of associated Legendre function in the Eq. (6) are used, it is not difficulty. The orthogonal properties of function on the Eq. (6) can be written from the article (Winch et al. 2005) as

$$
\begin{aligned}
& \int_{0}^{2 \pi} \int_{0}^{\pi} \mathrm{P}_{\mathrm{n}}^{\mathrm{m}}(\theta) \mathrm{P}_{\mathrm{N}}^{\mathrm{M}}(\theta) \cos (\mathrm{m} \varphi) \cos (\mathrm{M} \varphi) \sin (\theta) \mathrm{d} \theta \mathrm{d} \varphi \\
& =\frac{4 \pi}{2 \mathrm{n}+1} \delta_{\mathrm{n}}^{\mathrm{N}} \delta_{\mathrm{m}}^{\mathrm{M}} \\
& \int_{0}^{2 \pi} \int_{0}^{\pi} \mathrm{P}_{\mathrm{n}}^{\mathrm{m}}(\theta) \mathrm{P}_{\mathrm{N}}^{\mathrm{M}}(\theta) \sin (\mathrm{m} \varphi) \sin (\mathrm{M} \varphi) \sin (\theta) \mathrm{d} \theta \mathrm{d} \varphi \\
& =\frac{4 \pi}{2 \mathrm{n}+1} \delta_{\mathrm{n}}^{\mathrm{N}} \delta_{\mathrm{m}}^{\mathrm{M}}, \\
& \int_{0}^{2 \pi} \int_{0}^{\pi} \mathrm{P}_{\mathrm{n}}^{\mathrm{m}}(\theta) \mathrm{P}_{\mathrm{N}}^{\mathrm{M}}(\theta) \cos (\mathrm{m} \varphi) \sin (\mathrm{M} \varphi) \sin (\theta) \mathrm{d} \theta \mathrm{d} \varphi=0
\end{aligned}
$$

and 


$$
\begin{gathered}
\int_{0}^{2 \pi} \int_{0}^{\pi}\left[\frac{\mathrm{dP}}{\mathrm{n} \theta}(\theta) \frac{d \mathrm{P}_{N}^{\mathrm{M}}(\theta)}{\mathrm{d} \theta} \cos (\mathrm{m} \varphi) \cos (\mathrm{M} \varphi)\right. \\
\left.+\frac{\mathrm{mM}}{\sin ^{2}(\theta)} \mathrm{P}_{\mathrm{n}}^{\mathrm{m}}(\theta) \mathrm{P}_{\mathrm{N}}^{\mathrm{M}}(\theta) \sin (\mathrm{m} \varphi) \sin (\mathrm{M} \varphi)\right] \\
\times \sin (\theta) \mathrm{d} \theta \mathrm{d} \varphi=\frac{4 \pi \mathrm{n}(\mathrm{n}+1)}{2 \mathrm{n}+1} \delta_{\mathrm{n}}^{\mathrm{N}} \delta_{\mathrm{m}}^{\mathrm{M}}
\end{gathered}
$$

The integral on the Eq. (8) could be divided two terms with $\left(\mathrm{g}_{\mathrm{n}}^{\mathrm{m}}\right)^{2}$ and $\left(\mathrm{h}_{\mathrm{n}}^{\mathrm{m}}\right)^{2}$ as

$\mathrm{W}=\mathrm{W}_{1}+\mathrm{W}_{2}$.

The first term $\left(\mathrm{W}_{1}\right)$ in Eq. (13) can be rewritten as

$$
\begin{aligned}
& \mathrm{W}_{1}=\frac{1}{2 \mu_{0}} \sum_{\mathrm{n}=1}^{\mathrm{k}} \int_{\mathrm{a}}^{\mathrm{a}+80}\left(\frac{\mathrm{a}}{\mathrm{r}}\right)^{2(\mathrm{n}+2)} \mathrm{r}^{2} \mathrm{dr} \\
& \times\left[\sum _ { \mathrm { m } = 0 } ^ { \mathrm { n } } ( \mathrm { g } _ { \mathrm { n } } ^ { \mathrm { m } } ) ^ { 2 } \int _ { 0 } ^ { 2 \pi } \int _ { 0 } ^ { \pi } \left[\left(\frac{\mathrm{dP} \mathrm{n}(\theta)}{\mathrm{d} \theta}\right)^{2} \cos ^{2}(\mathrm{~m} \varphi)\right.\right. \\
&+\frac{\mathrm{m}^{2}}{\sin ^{2}(\theta)}\left(\mathrm{P}_{\mathrm{n}}^{\mathrm{m}}(\theta)\right)^{2} \sin ^{2}(\mathrm{~m} \varphi) \\
&\left.\left.+(\mathrm{n}+1)^{2}\left(\mathrm{P}_{\mathrm{n}}^{\mathrm{m}}(\theta)\right)^{2} \cos ^{2}(\mathrm{~m} \varphi)\right] \sin (\theta) \mathrm{d} \theta \mathrm{d} \varphi\right]
\end{aligned}
$$

If the orthogonal properties on the Eqs. (9-12) are used, the expression in the Eq. (14) could be written as

$$
\begin{aligned}
\mathrm{W}_{1}= & \frac{1}{2 \mu_{0}} \sum_{\mathrm{n}=1}^{\mathrm{k}} \int_{\mathrm{a}}^{\mathrm{a}+80}\left(\frac{\mathrm{a}}{\mathrm{r}}\right)^{2(\mathrm{n}+2)} \mathrm{r}^{2} \mathrm{dr} \times \\
& {\left[\frac{4 \pi \mathrm{n}(\mathrm{n}+1)}{2 \mathrm{n}+1}+\frac{4 \pi(\mathrm{n}+1)^{2}}{2 \mathrm{n}+1}\right] \sum_{\mathrm{m}=0}^{\mathrm{n}}\left(\mathrm{g}_{\mathrm{n}}^{\mathrm{m}}\right)^{2} . }
\end{aligned}
$$

And the second term $\left(\mathrm{W}_{2}\right)$ of the Eq. (13) could be written as

$$
\mathrm{W}_{2}=\frac{1}{2 \mu_{0}} \sum_{\mathrm{n}=1}^{\mathrm{k}} \int_{\mathrm{a}}^{\mathrm{a}+80}\left(\frac{\mathrm{a}}{\mathrm{r}}\right)^{2(\mathrm{n}+2)} \mathrm{r}^{2} \mathrm{dr} \times 4 \pi(\mathrm{n}+1) \sum_{\mathrm{m}=0}^{\mathrm{n}}\left(\mathrm{h}_{\mathrm{n}}^{\mathrm{m}}\right)^{2} .
$$

Now, the Eq. (13) could be rewritten in the following form

$$
\begin{aligned}
\mathrm{W}= & \mathrm{W}_{1}+\mathrm{W}_{2} \\
= & \frac{1}{2 \mu_{0}} \sum_{\mathrm{n}=1}^{\mathrm{k}} \int_{\mathrm{a}}^{\mathrm{a}+80}\left(\frac{\mathrm{a}}{\mathrm{r}}\right)^{2(\mathrm{n}+2)} \mathrm{r}^{2} \mathrm{dr} \times 4 \pi(\mathrm{n}+1) \\
& \times \sum_{\mathrm{m}=0}^{\mathrm{n}}\left[\left(\mathrm{g}_{\mathrm{n}}^{\mathrm{m}}\right)^{2}+\left(\mathrm{h}_{\mathrm{n}}^{\mathrm{m}}\right)^{2}\right] .
\end{aligned}
$$

The total energy of geomagnetic field is expressed by the Eq. (17). The values of Gaussian coefficients $\left(\mathrm{g}_{\mathrm{n}}^{\mathrm{m}}, \mathrm{h}_{\mathrm{n}}^{\mathrm{m}}\right)$ in the Eq. (17) are taken from the website (doi: 10.1111/j.1365-246X.2010.04804.x).

\section{Results and discussion}

The Eq. (17) could be called "the formula of total energy of geomagnetic field". The total energy of geomagnetic field can be solved by the Eq. (17) in the interesting volume from the Earth's surface to unlimited space. The values of Gaussian coefficients in the Eq. (17) are determined by measured values on the Earth's the surface and satellites in orbits about Earth. Therefore we think that the formula in the Eq. (17) fits clearly in the volume from the Earth's surface to the ionosphere. We are also very interesting the power of geomagnetic field about surface of Earth. Thus the total energy of geomagnetic field is solved in the volume from the Earth's surface $(\mathrm{a}=6371.2 \mathrm{~km})$ to the ionosphere $(\mathrm{a}+80 \mathrm{~km})$ in this paper. Values of the total energy solved by the Eq. (17) are written on the Table 1.

The dependence on time of total energy of geomagnetic field is depicted on the Fig. 1. There are two types of dependence on time in the Fig. 1. The first type is linear and it is expressed as

$\mathrm{E}_{1}(\mathrm{t})=(-0.002995 \mathrm{t}+3.370262) \times 10^{16}$.

The power of geomagnetic field could be solved from the Eq. (18) as

$\mathrm{P} \approx \mathrm{P}_{1}=\left|\frac{\mathrm{dE}_{1}(\mathrm{t})}{\mathrm{dt}}\right|=0.002995 \times 10^{16}\left[\frac{\text { Joule }}{\text { year }}\right]$ 
Table 1 Values of the total energy are solved by the Eq. (17)

\begin{tabular}{llllll}
\hline Years & Energy $\times 10^{16}[$ Joule $]$ & Years & Energy $\times 10^{16}$ [Joule] & Years & Energy $\times 10^{16}[$ Joule $]$ \\
\hline 1900 & 3.385087 & 1940 & 3.235077 & 1980 & 3.13329 \\
1905 & 3.371507 & 1945 & 3.229068 & 1985 & 3.111704 \\
1910 & 3.352547 & 1950 & 3.226016 & 1990 & 3.094312 \\
1915 & 3.327113 & 1955 & 3.219851 & 1995 & 3.079873 \\
1920 & 3.299366 & 1960 & 3.207295 & 2000 & 3.066554 \\
1925 & 3.275573 & 1965 & 3.193069 & 2005 & 3.054352 \\
1930 & 3.255545 & 1970 & 3.173094 & 2010 & 3.043091 \\
1935 & 3.24233 & 1975 & 3.151597 & 2015 & \\
\hline
\end{tabular}

Fig. 1 The dependence on time of the total energy of geomagnetic field

Fig. 2 The periodical dependence on time in the total energy of geomagnetic field
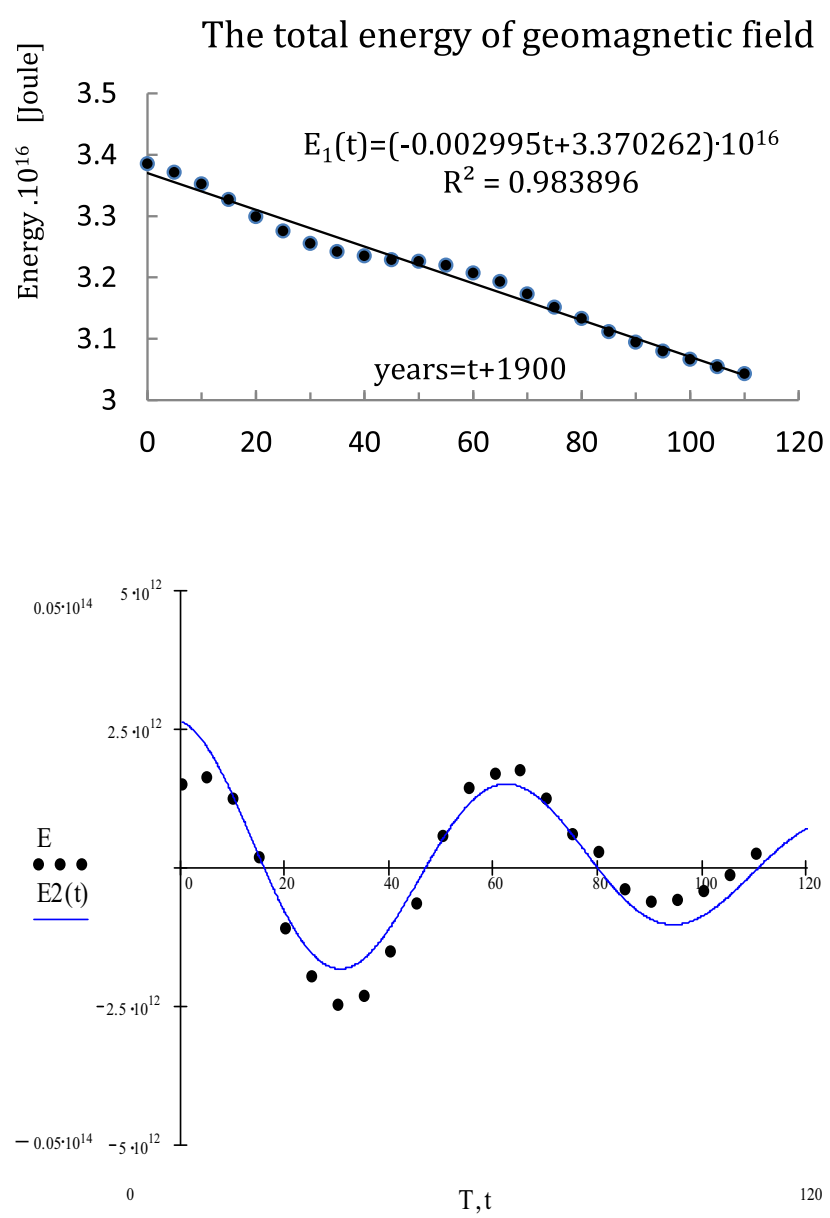

where P-is power of geomagnetic field about surface of Earth.

$\mathrm{P}=\left|\frac{\mathrm{dE}_{1}(\mathrm{t})}{\mathrm{dt}}\right|=\frac{0.002995 \times 10^{16} \text { Joule }}{365 \times 24 \times 3600 \mathrm{sec}} \approx 949.7 \mathrm{~kW}$.

Now, the unit of the power must be expressed by the 
If the total energy of geomagnetic field is changed clearly by the linear decreasing law as the Eq. (18), it must be equaled zero after 1126 years or in 3026. But geomagnetic field of Earth has been existed during the last three billion years. Thus, the linear decreasing form on the Fig. 1 could be a small part, which is appeared in the linear form, of any oscillation with the very long period such as longer than 600 years.

If the linear dependence on time is subtracted from the Fig. 1, the clear periodical dependence on time in the energy could be differed. Its analytic form could be obtained by the least square method as

$E_{2}(t)=\left(a_{1} \times e^{-\beta t} \sin \left(a_{2} t-a_{3}\right)+a_{4}\right) \times 10^{14}$,

where $\mathrm{t}$ is time or variable, and $\mathrm{a}_{1}=0.025219512$, $\beta=0.00892494537, \quad \mathrm{a}_{2}=0.098482076, \quad \mathrm{a}_{3}=$ -1.62740646 and $\mathrm{a}_{4}=-0.04020871$ are parameters. It is depicted on the Fig. 2. The coefficient of determination of Eq. (21) is $\mathrm{R}^{2}=0.9037$. The function in Eq. (21) is a damping oscillation. In other word, the amplitude of oscillation on the Fig. 2 is decreasing. The periodical dependence on time in the Fig. 2 could be a part with 110 years of a large damping oscillation.

\section{Conclusions}

Generally, the total energy of geomagnetic field is decreasing along to the line expressed in the Eq. (18) as the Fig. 1. The general power of geomagnetic field was also steady about $949.7 \mathrm{~kW}$ in the years (1900-2010). Therefore, the variation of the power of geomagnetic field about Earth's surface could be equaled zero in the few years. This condition, which the variation of the power equals zero in the few years, is mathematical main condition to solve the drift of geomagnetic field about Earth's surface.

Two types of dependencies on time are observed in the total energy of geomagnetic field. The first type is the linear decreasing form as the Eq. (18). The second type is the damping oscillation form with about 60 year's period on the Fig. 2.

We think that the linear decreasing form could be the variation of the strong field sourced at the center of the Earth's inner core. Maybe the total energy of geomagnetic field is an opportunity to study the properties of the strong field.

However, the damping oscillation with about 60 year's period could be sourced by the fluid motions on the core mantle boundary (CMB). In other words, the effects of the fluid motions on CMB could be appeared as the damping oscillation form in the total energy of geomagnetic field about Earth's surface.

Open Access This article is distributed under the terms of the Creative Commons Attribution 4.0 International License (http:// creativecommons.org/licenses/by/4.0/), which permits unrestricted use, distribution, and reproduction in any medium, provided you give appropriate credit to the original author(s) and the source, provide a link to the Creative Commons license, and indicate if changes were made.

\section{References}

Finlay CC, Maus S, Beggan CD, Bondar TN, Chambodut A, Chernova TA, Chulliat A, Golovkov VP, Hamilton B, Hamoudi M, Holme R, Hulot G, Kuang W, Langlais B, Lesur V, Lowes FJ, Lühr H, Macmillan S, Mandea M, McLean S, Manoj C, Menvielle M, Michaelis I, Olsen N, Rauberg J, Rother M, Sabaka TJ, Tangborn A, TøffnerClausen L, Thébault E, Thomson AWP, Wardinski I, Wei Z, Zvereva TI (2010) International association of geomagnetism and aeronomy, working group V-MOD, international geomagnetic reference field: the eleventh generation. Geophys J Int 183:1216-1230. doi:10.1111/j. 1365-246X.2010.04804.x

Herndon JM (2009) Uniqueness of Herndon's georeactor: energy source and production mechanism for Earth's magnetic field. (arXiv.org/abs/0901.4509)

Winch DE, Ivers DJ, Turner JPR, Stening RJ (2005) Geomagnetism and schmidt quasi-normalization. Geophys J Int 160:487-504. doi:10.1111/j.1365-246X.2004.02472.x 